\title{
Variantes de lesões intra-epiteliais escamosas: relato de quatro casos
}

\section{Variants of intraepithelial squamous lesions: report of four cases}

Álvaro P. Pinto'; Leandro Mutschall'; Hercílio Fronza Júnior³; Felipe Francisco Bondam Tuon; Guilherme Barroso Guedes ${ }^{5}$; Jorge Ricardo Paqueira ${ }^{6}$

\begin{abstract}
unitermos resumo
Lesões intra-epiteliais

Entre a rotina de biópsias e produtos cirúrgicos provenientes do colo uterino, um número significativo

escamosas

de lesões intra-epiteliais escamosas (LIE) pode causar dificuldade quanto a caracterização e graduação

Papilomavirus humano

histológica. Tais lesões têm sido identificadas e descritas isoladamente por artigos científicos como

Colo uterino

variantes histológicas de LIE cervicais. São elas a metaplasia papilar imatura atípica (MPIA) e as varian-

Variantes

tes de neoplasia intra-epitelial cervical graus II/III: queratinizante, com padrão metaplásico imaturo

de crescimento e escamomucinosa. Neste artigo são exemplificados quatro casos representativos das

Hibridização in situ entidades citadas acima, provenientes das rotinas do Programa de Prevenção do Câncer Ginecológico do Estado do Paraná e de um laboratório privado especializado em patologia ginecológica de Curitiba, o Laboratório de Citopatologia e Anatomia Patológica Annalab. Os principais critérios diagnósticos são descritos, assim como a correlação citológica e molecular relacionada à presença e à localização do ácido nucleico viral (papilomavírus humano [HPV]) nas lesões.
\end{abstract}

In routine basis, among biopsies and surgical specimens derived from uterine cervix, a significant number of squamous intraepithelial lesions (SIL) may be difficult to diagnose and grade. Some of these lesions were identified, isolated and reported in scientific articles as histological variants of SIL. They are: metaplastic papillary immature atypia (MPIA) and the following grade II/III cervical intraepithelial neoplasia variants: keratinized, immature metaplastic-like proliferation and mucin-producing. In this article four cases representative of these variants are described. They were retrieved from the routines of a large scale gynecological cancer screening program and a private laboratory specialized on gynecological pathology, both from Paraná State, Brazil. The main histological criteria for diagnosis are described, as well cytological and molecular correlation related to presence and localization of viral nucleic acid (human papilloma virus) in lesion sections.

key words

Squamous intraepithelial

lesions

Human papillomavirus

Uterine cervix

Variants

In situ hybridization

\footnotetext{
1. Médico; professor-adjunto do Departamento de Patologia Médica do Setor de Ciências da Saúde da Universidade Federal do Paraná (UFPR); doutor em Patologia pela Faculdade de Medicina da Universidade de São Paulo (FMUSP); ginecopatologista do Serviço de Anatomia Patológica do Hospital de Clínicas da UFPR, do Laboratório de Citopatologia e Anatomia Patológica Annalab e dos Serviços Integrados de Patologia (SIP).

2. Biólogo; responsável técnico pelo setor de biologia molecular do SIP.

3. Médico; especialista em Patologia e Citopatologia; diretor do SIP.

4. Médico; residente de Clínica Médica do Hospital Universitário Evangélico de Curitiba (HUEC).

5. Acadêmico de Medicina do nono período da UFPR; bolsista do Conselho Nacional de Desenvolvimento Científico e Tecnológico (CNPq).

6. Acadêmico de Medicina do décimo período da UFPR; estagiário do Laboratório Annalab.

Trabalho realizado no Serviço de Anatomia Patológica do HC/UFPR, Curitiba (PR); no Laboratório de Citopatologia e Anatomia Patológica Annalab S/C Ltda., Curitiba (PR); e no SIP, Joinville (SC).
} 


\section{Introdução}

A histologia das lesões intra-epiteliais escamosas (LIE) cervicais pode apresentar variantes morfológicas de difícil caracterização. $\mathrm{O}$ ainda escasso conhecimento acumulado sobre estas LIE pode levar a interpretação e diagnóstico errôneos.

Em pesquisa realizada anteriormente, investigando a correlação cito-histológica de casos caracterizados citologicamente como atípicos de significado indeterminado (ASCUS), alguns casos foram identificados ${ }^{(19)}$. Estima-se que até $10 \%$ das lesões caracterizadas como intra-epiteliais de alto grau (LIAG) podem se tratar de variantes de difícil caracterização morfológica ${ }^{(4)}$. Entre estas variantes, as mais características são a metaplasia papilar imatura atípica, a neoplasia intra-epitelial cervical (NIC) graus II/III variante queratinizante, a NIC III variante com padrão metaplásico imaturo de crescimento e a variante escamomucinosa.

Foram selecionados, entre os casos de cirurgia de alta freqüência (CAF) do Programa de Prevenção do Câncer Ginecológico do Estado do Paraná e as biópsias do Laboratório de Citopatologia e Anatomia Patológica Annalab, quatro casos representativos destas entidades morfológicas.

\section{Relato dos casos}

\section{Caso 1}

D.P.T., 30 anos, solteira. Ao exame especular foi evidenciada lesão polipóide endocervical sangrante. Hipótese diagnóstica clínica: pólipo endocervical. Realizada retirada da lesão para análise histopatológica e colhido exame citológico cervicovaginal concomitante que resultou negativo. A lesão foi diagnosticada como metaplasia papilar imatura atípica - lesão intra-epitelial de baixo grau (LIBG) - pelo exame histopatológico. Dois meses após a retirada da lesão, a paciente retornou ao laboratório para a realização de teste molecular para papilomavírus humano (HPV) (captura híbrida) para controle de possível recidiva. O exame foi positivo para a presença de HPVs do grupo A (baixo risco), sendo a carga viral baixa, RPCLU 3,2 (unidade relativa de luz).

\section{Caso 2}

A.F., 38 anos. Ao exame colposcópico evidenciou-se extensa área de leucoplasia com aspecto micropapilar, sugestiva de NIC ou carcinoma invasor. O exame citológico cervicovaginal resultou em LIBG e desvio da flora bacteriana com predomínio de cocobacilos. A análise histológica da biópsia revelou NIC II e alterações condizentes com infecção pelo HPV. Realizada CAF, o exame histológico revelou NIC II/III variante queratinizante com foco de microinvasão de $1,4 \mathrm{~mm}$ de profundidade e 0,4mm de extensão lateral e ausência de comprometimento vascular. As margens cirúrgicas ectocervical e endocervical encontravam-se comprometidas pela lesão intra-epitelial. Foi realizada nova CAF três meses após a primeira, e o exame anatomopatológico revelou novamente NIC II/III queratinizante, desta vez estando com as margens livres.

\section{Caso 3}

M.T.F.S., 29 anos. Colposcopia anormal, sugestiva de NIC. O exame citológico cervicovaginal resultou em NIC III. Realizada CAF que, na histologia da peça, revelou NIC III com padrão metaplásico imaturo de crescimento - proliferação escamosa imatura atípica cervical. Margem cirúrgica ectocervical comprometida pela LIE e margem endocervical livre. No seguimento, os exames citológicos cervicovaginais subseqüentes foram negativos.

\section{Caso 4}

C.K., 48 anos. Ao exame físico percebeu-se útero aumentado de volume, com massas palpáveis condizentes com leiomiomas intramurais. Ao exame colposcópico revelou-se zona de transformação atípica, com vasos atípicos e epitélio espessado, sugestivo de LIAG. Realizada biópsia de colo uterino. O exame histopatológico evidenciou NIC III variante escamomucinosa. Não foram conseguidas informações a respeito do seguimento deste caso.

\section{Discussão}

\section{Caso 1 - Metaplasia papilar imatura atípica}

A MPIA é uma variante pouco comum das LIBG. Descrita inicialmente por Crum et al. ${ }^{(4)} \mathrm{em}$ produtos de conização, esta entidade é uma exceção ao conceito de que as lesões intra-epitelias escamosas imaturas devem ser interpretadas histologicamente como LIAG.

Ao exame colposcópico, essas lesões costumam apresentar-se de forma semelhante à condilomatose de colo uterino, exibindo áreas com epitélio esbranquiçado e morfologia vegetante ou papilífera.

O diagnóstico citológico é difícil, e os exames citopatológicos são freqüentemente interpretados como ASCUS ${ }^{(11)}$ ou considerados dentro dos padrões de normalidade. Os aspectos citológicos identificáveis são o de células metaplásicas imaturas com graus variáveis de atipia e a presença de binucleação. Contudo, o diagnóstico de MPIA não pode ser realizado apenas com base nos achados citopatológicos ${ }^{(3,}$ 11). As técnicas moleculares de detecção do HPV permitem 
identificar o tipo de vírus envolvido com o aparecimento das lesões, e geralmente são observados HPVs de baixo potencial oncogênico, principalmente dos tipos 6 e 11, que estão presentes em aproximadamente $76 \%$ dos $\operatorname{casos}^{(3,21,22)}$. Em alguns casos, a identificação de HPVs de alto potencial oncogênico é relatada ${ }^{(22)}$.

A histopatologia parece ser o método diagnóstico que melhor caracteriza a lesão. A MPIA apresenta, histologicamente, áreas de proliferação celular escamosa imatura de aspecto papilífero, com atipia citológica variável e tendência a estender-se pelo canal endocervical. Difere do condiloma típico por não apresentar coilocitose e outros sinais histológicos de infecção viral. Ainda segundo a literatura, estas lesões, quando amostradas extensamente, revelam com freqüência áreas de condiloma típico ${ }^{(11,22)}$. Menos comum é a presença de LIAC concomitante, que pode ocorrer em até $23 \%$ dos casos.

A Figura 1 demonstra o aspecto panorâmico da lesão aqui relatada, com eixos fibrovasculares ramificados delicados revestidos por epitélio escamoso delgado. Na Figura 2 (detalhe), é possível perceber a imaturidade do epitélio escamoso, bem como as atipias nucleares. Conforme mencionado anteriormente, o exame citológico destes casos freqüentemente resulta no diagnóstico de ASCUS ou negativo para a lesão. A Figura 3 demonstra célula metaplásica imatura com aumento de volume nuclear e hipercromasia, suficientes no máximo para o diagnóstico de ASCUS.

Em nossa experiência, a MPIA pode ser identificada por exame colposcópico ou cervicográfico, e pode ser precedida do diagnóstico de ASCUS ou da deteç̧ão de HPV por teste molecular. A caracterização histológica precisa destas lesões como de baixo grau evita o tratamento desnecessário por conização ou cirurgia de alta freqüência. $O$ reconhecimento adequado desta entidade é necessário para que se estabeleça o diagnóstico correto e se proceda à conduta terapêutica mais apropriada.

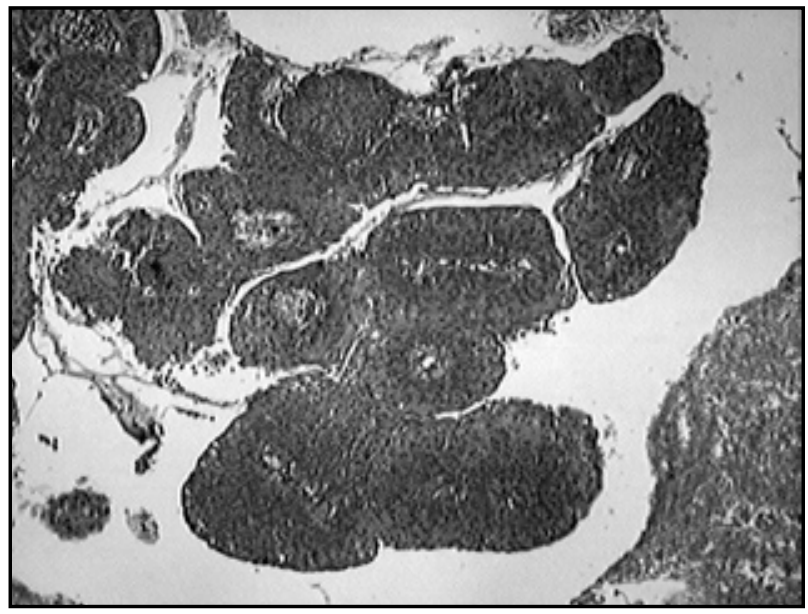

Figura 1 - MPIA: eixos fibrovasculares ramificados constituindo papilas (40x)

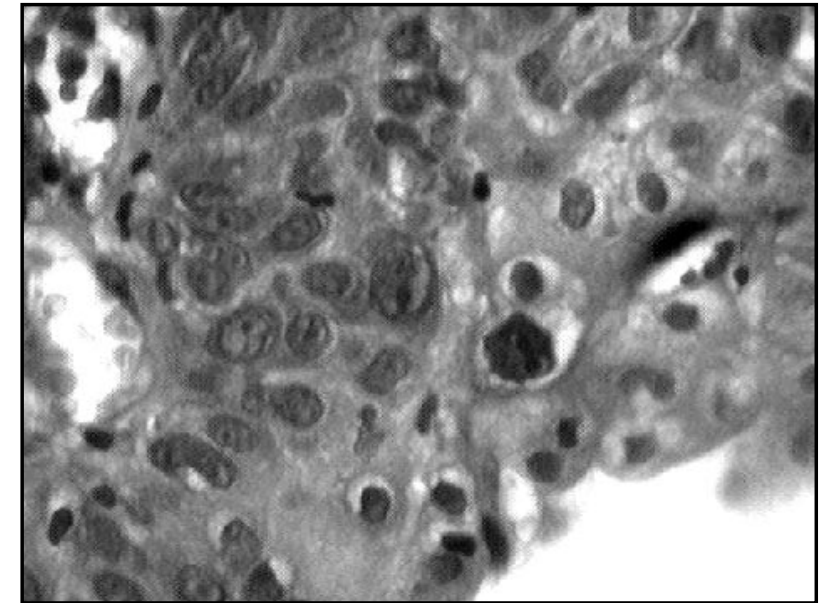

Figura 2 - MPIA: revestimento epitelial da papila por epitélio escamoso imaturo. Presença de atipia epitelial (400x)

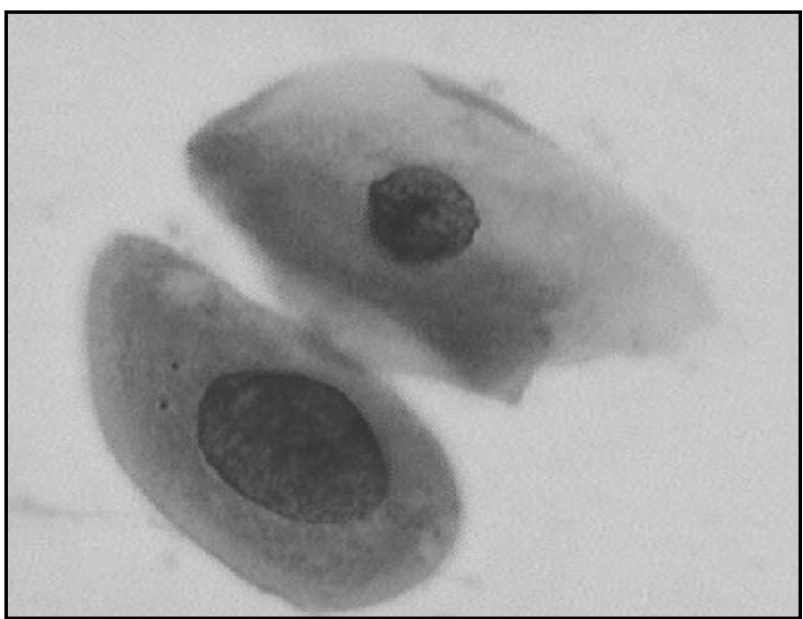

Figura 3 - MPIA: aspecto citológico, célula escamosa metaplásica imatura com discreta hipercromasia nuclear, célula escamosa intermediária normal para comparação (400x)

\section{Caso 2 - NIC II/III variante queratinizante}

Após revisar cem exames citológicos de Papanicolaou contendo lesões escamosas queratinizantes intra-epiteliais, usando critérios citológicos padrões, Faquin et al.(5) verificaram baixa concordância interobservador. Para algumas dessas lesões os autores recomendaram o diagnóstico de LIE acrescido de uma observação de que a graduação da lesão não seria possível em conseqüência de extensa queratinização. Por outro lado, outro estudo ${ }^{(12)}$ concluiu que a diferenciação citológica entre alterações associadas a queratinização anormal benigna e relacionadas a LIE pode ser feita consistentemente por meio da observação do grau de hiperceratose, padrão de contorno, hipercromasia nuclear e crescimento das células disceratóticas. Desta forma, podemos supor que, a partir de esfregaços cervicovaginais, este tipo de variante de LIE seja difícil de se graduar, mas não de se reconhecer e diferenciar de processos reacionais. 
Outro diagnóstico diferencial a ser feito é com o carcinoma escamoso invasor, que pode mimetizar citologicamente esta lesão, porém apresenta geralmente diátese tumoral e células atípicas com formatos bizarros e nucléolos proeminentes ${ }^{(4)}$. No caso aqui relatado, um foco de microinvasão foi revelado no exame histológico do produto da CAF. Entretanto, células com alterações condizentes com invasão não foram observadas, mesmo após a revisão da amostra citológica que rastreou originalmente a lesão. Histologicamente, a neoplasia intra-epitelial cervical queratinizante exibiu atipia nuclear evidente nas camadas inferiores e intermediárias da lesão, de maneira similar a lesões não-queratinizantes (Figura 4). A confirmação da etiologia viral desta lesão pôde ser comprovada através do método molecular de hibridização in situ (HIS) para HPV, utilizando-se uma sonda de amplo espectro (Figura 5). O exame citopatológico do caso revelou células escamosas superficiais atípicas, sendo difícil a caracterização e a graduação da lesão a partir da amostra (Figura 6).

\section{Caso 3 - NIC III com padrão metaplásico imaturo de crescimento}

Embora algumas lesões escamosas imaturas do colo uterino, como a MPIA, vista anteriormente, tenham sido descritas e associadas com HPV, a proliferação escamosa imatura atípica não papilar (AISP) é uma entidade mal definida que varia de metaplasia reacional atípica a LIE semelhante a metaplasia imatura, denominada aqui de LIAC com padrão metaplásico imaturo de crescimento.

Alguns estudos examinaram a reprodutibilidade do diagnóstico de AISP e a relação deste com a presença de DNA de HPV $(9,14,20)$. Microscopicamente, AISP compreende um grupo morfologicamente heterogêneo de lesões que desafia uma classificação precisa. Seu aspecto histopatológico não se correlaciona consistentemente com a presença de HPV. O manejo laboratorial de casos de AISP deveria levar em conta a incerteza deste diagnóstico. Um teste molecular de HPV pode ser fundamental como complemento deste

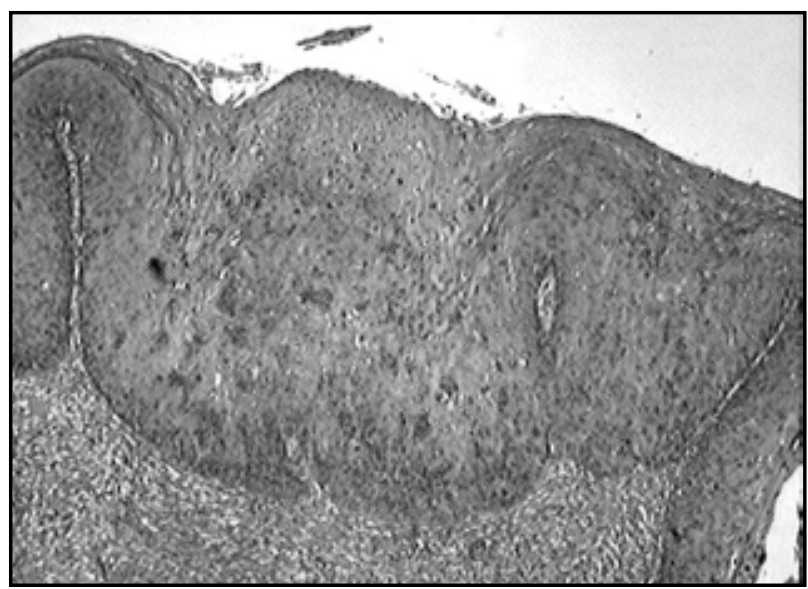

Figura 4 - LIAG queratinizante: acantose, hiperceratose e papilomatose (40x) diagnóstico. Todavia isto ainda está para ser esclarecido por futuros estudos. O caso aqui apresentado, apesar de seu aspecto histológico monótono com imaturidade do epitélio, não representa grande desafio diagnóstico (Figura 7). Todavia esta variante, assim como a lesão escamomucinosa, pode apresentar-se como um espectro de alterações que variam de epitélio metaplásicos imaturos atípicos reacionais a lesões mais bem caracterizadas. É importante salientar que os casos aqui relatados são representantes da extremidade pré-cancerosa deste espectro. Dependendo das características da lesão, um teste molecular pode ser necessário para a definição do diagnóstico. No caso aqui apresentado, foi realizada a HIS com sonda de amplo espectro, o que confirmou o envolvimento do HPV e o diagnóstico da variante de lesão intra-epitelial (Figura 8).

\section{Caso 4 - NIC III variante escamomucinosa}

Apesar da ausência de valor prognóstico(8), relação com a idade ${ }^{(2)}$ ou outro fator epidemiológico, carcinomas

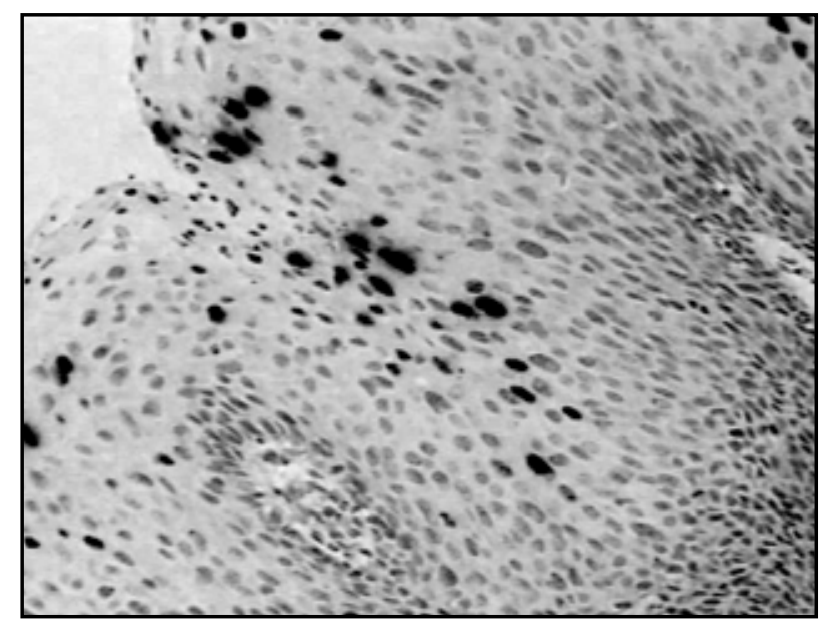

Figura 5 - LIAG queratinizante: núcleos positivos (em castanho) confirmando a infecção pelo HPV através da técnica de hibridização in situ, utilizando-se sonda de amplo espectro (100x)

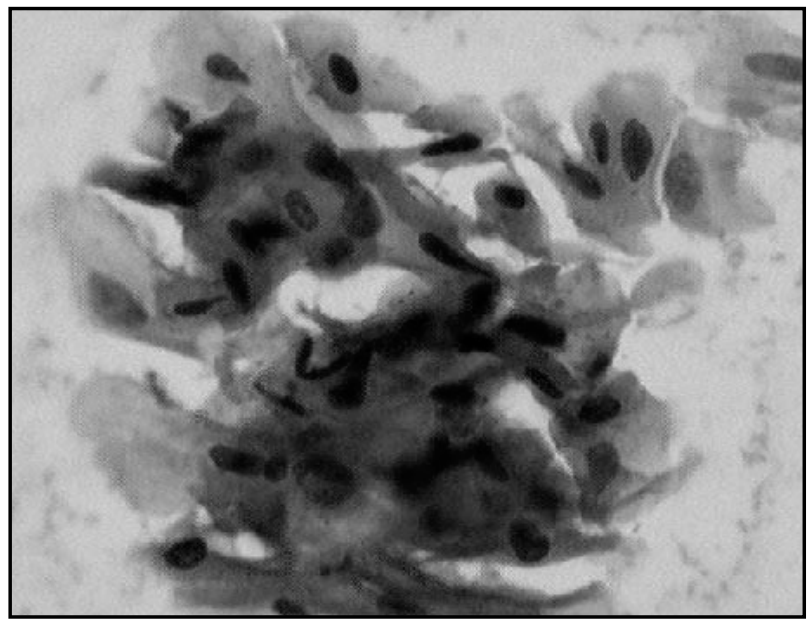

Figura 6 - LIAG queratinizante: aspecto citológico, grupamento em placa de células disceratóticas com atipia proeminente (100x) 
escamosos secretores de mucina são reconhecidos como uma categoria específica em classificações histológicas de carcinoma cervical, e denominados carcinomas adenoescamosos (sistema da Organização Mundial da Saúde [OMS]) ou carcinomas escamosos com secreção de mucina (sistema proposto por Fox). Por outro lado, neoplasias intra-epiteliais escamosas (NIC) e glandulares (adenocarcinoma in situ [AIS]) coexistem freqüentemente no mesmo espécime cervical. A produção de mucina em NIC foi descrita há vários anos para apoiar a hipótese de que carcinomas adenoescamosos invasivos surgem de uma célula de reserva indiferenciada ${ }^{(6)}$. Mais recentemente ${ }^{(15)}$, esta variante de LIE foi descrita em maior detalhe. Consiste num epitélio estratificado que se assemelha a NIC, no qual a produção de mucina está presente (Figuras 9 e 10) (lesões intra-epiteliais produtoras de mucina [SMILE]). SMILE é uma lesão intra-epitelial cervical incomum que surge a partir das células de reserva da zona de transformação.

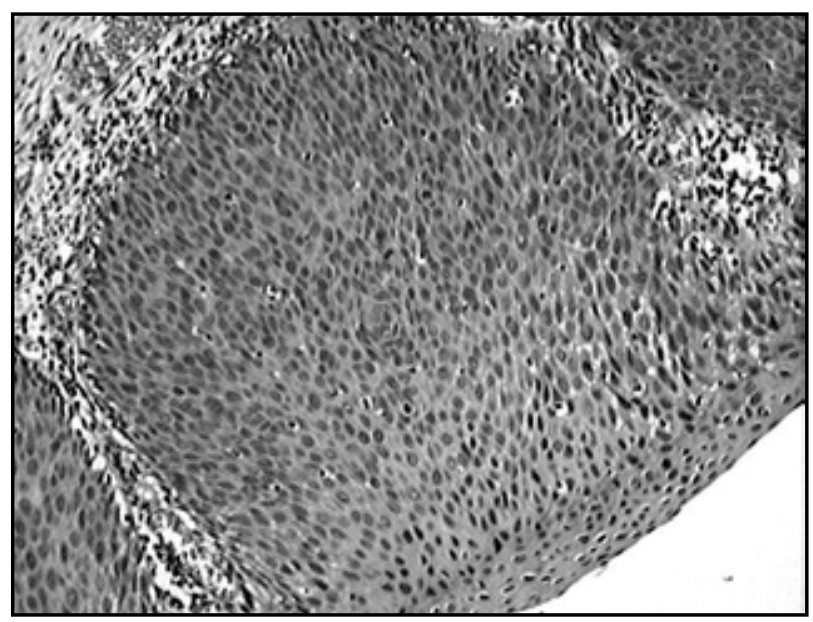

Figura 7 - LIAG com padrão metaplásico de crescimento: aspecto uniforme e monótono dos núcleos da lesão (40x)

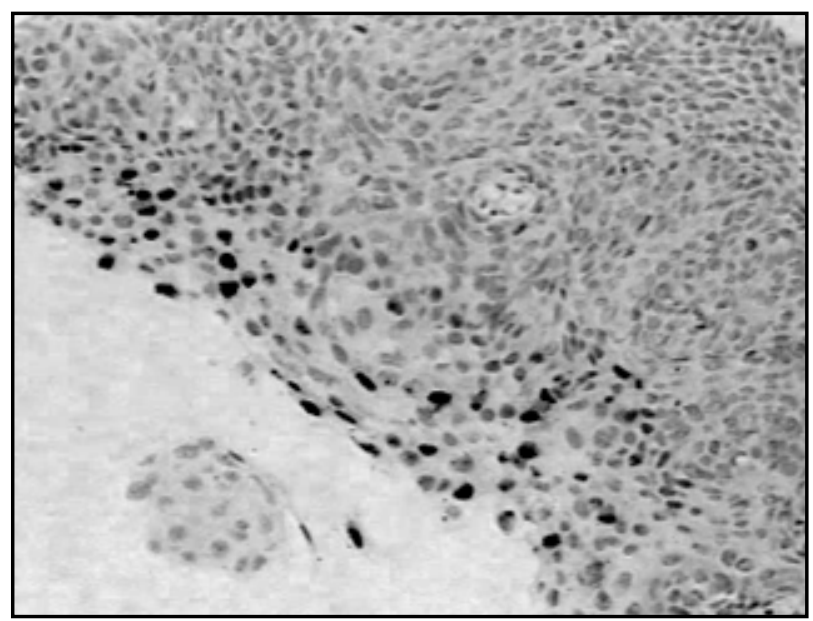

Figura 8 - LIAG com padrão metaplásico de crescimento: comprovação do envolvimento do HPV na etiologia da lesão através de sonda de amplo espectro na HIS (100x)
Com base em seu fenótipo imunológico e na presença de lesões invasivas coexistentes (adenocarcinomas, carcinomas adenoescamosos ou ambos), esta lesão é mais bem classificada como uma variante de AIS $^{(15)}$. A coexistência de um largo espectro de fenótipos celulares intra-epiteliais e invasivos sugere que SMILE seja um marcador para instabilidade fenotípica e enfatiza a importância da identificação desta variante de LIE, assegurando um exame completo de espécimes que contêm esta lesão precursora incomum de carcinomas cervicais.

O HPV atua como principal fator etiológico das lesões precursoras e do câncer cervical, e as lesões acima parecem não ser exceção a esta regra. Recentemente, muitas técnicas têm sido desenvolvidas visando a documentar a presença do HPV em amostras celulares cervicais ${ }^{(7)}$. A grande aplicabilidade do diagnóstico do HPV em esfregaços cervicovaginais e biópsias de colo uterino está na elucidação de casos de difícil diagnóstico. Evitam-se, assim, erros que podem levar

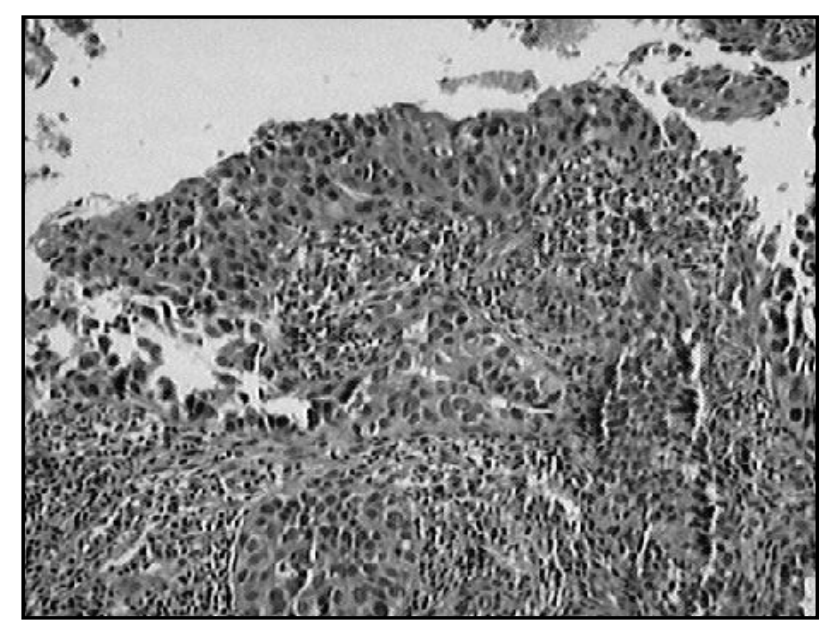

Figura 9 - LIAG escamomucinosa: epitélio estratificado imaturo revestindo superfície e glândulas (40x)

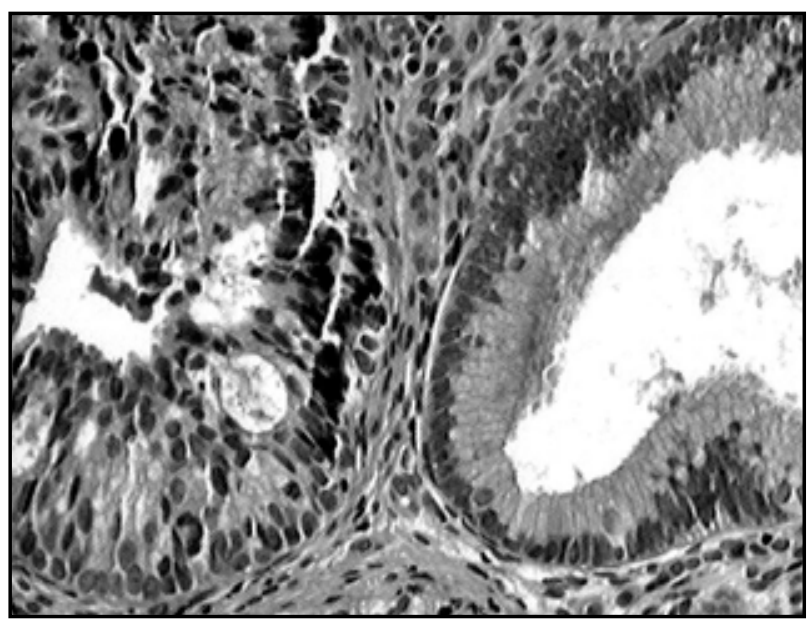

Figura 10 - LIAG escamomucinosa: glândula substituída por lesão e glândula preservada. Na lesão evidenciam-se sobreposição, atipias, aspecto cribriforme e espaçamento nuclear com áreas claras (acúmulo de muco) (100x) 
pacientes a tratamentos inadequados. Por outro lado, proporciona aos patologistas, parâmetros para o aprendizado de critérios diagnósticos. Estas técnicas podem ser tanto de amplificação de ácidos nucleicos (reação em cadeia de polimerase [PCR]), como de métodos de hibridização de ácidos nucleicos (southern blot, dot blot, hibridação in situ por fluorescência (FISH), captura híbrida, entre outras). A HIS, apesar da sua baixa sensibilidade (20 a 50 cópias por célula), quando comparada com outras técnicas moleculares in vitro e de amplificação gênica, tem a vantagem de permitir a localização tecidual da infecção pelo $\mathrm{HPV}^{(1,10)}$.

Mesmo considerando a escassez de informações na literatura a respeito da etiologia, da patogenia e da evolução natural das lesões descritas acima, é importante salientarmos que o reconhecimento e a graduação corretos destes casos como lesão intra-epitelial são relevantes. Cabe a estudos futuros a ampliação do conhecimento a seu respeito, como a caracterização definitiva destas entidades.

\section{Referências}

I. BIBBO, M.; FILHO, M. A. S. Lesões relacionadas à infecção por HPV no trato anogenital. Rio de Janeiro: Editora Revinter, 1998, p. 37.

2. COLGAN,T. J:; AUGER, M.; MCLAUGHLIN, J. R. Histopathologic classification of cervical carcinomas and recognition of mucin-secreting squamous carcinomas. Int / Gynecol Pathol, v. 12, n. I, p. 64-9, 1993

3. CRUM, C. R. et al. Atypical immature metaplasia (AIM). A subset of human papilloma virus infection of the cervix. Cancer, v. I5, n. I2, p. 22। 4-9, 1983.

4. CRUM, C. R. et al. Pathology of early cervical neoplasia. In: Contemporary issues in surgical pathology. New York: Churchill Livingstone, | 997. vol. 4, p. 58-61.

5. FAQUIN, W. C. et al. Extensively keratinized squamous intraepithelial lesions of the cervix are difficult to grade. Am J Clin Pathol, v. I I 5, n. I, p. 80-4, 200 I.

6. FORDER, M. D.;TILTMAN,A. J. S. Mucin production in cervical intraepithelial neoplasia. Afr Med J, v. 81, n. 3, p. I55-6, 1992

7. KOSS, L. G. Diagnostic cytology. 4. ed. New York: Lippincott, 1992. vol. 2. p. I567-8.

8. LANGLOIS, N. E.; ELLUL, B.; MILLER, I. D. A study of the value and prognostic significance of mucin staining in squamous cell carcinoma of the uterine cervix. Histopathology, v. 28, n. 2, p. $175-8,1996$.

9. MITTAL, K.Atypical immature metaplastic-like proliferation of the cervix. Hum Pathol, v. 3I, n. 9, p. I 179-80, 2000.

I0. MONSONEGO, J. Papillomavirus in human pathology. Paris:AresSerono Symposia, 1995. p. 499.

I I. MOSHER, R. E. et al. Cytologic correlates of papillary immature metaplasia (immature condyloma) of the cervix. Diagn Cytopathol, v. 18, n. 6, p. 416-21, 1998.

12. NAVARRO, M. et al. Cytologic correlates of benign versus dysplastic abnormal keratinization. Diagn Cytopathol, v. 17 , n. 6, p. 447-5I, 1997.

13. PAPANICOLAOU, G. N.; TRAUT, H. F. The diagnostic value of vaginal smears in carcinoma of the uterus. Am J Obstet Gynecol, v. 42, p. 193-206, 1941.
14. PARK, J.J. et al. Atypical immature metaplastic-like proliferations of the cervix: diagnostic reproducibility and viral (HPV) correlates. Hum Pathol, v. 30, n. 10, p. I |61-5, 1999.

I5. PARK, J. J. et al. Stratified mucin-producing intraepithelial lesions of the cervix:adenosquamous or colunar cell neoplasia? Am J Surg Pathol, v. 24, n. 10, p. |4|4-9, 2000.

16. PINTO, A. P.; COLLACCO, L. M. Revisão das alterações citomorfológicas da infecção do vírus do papiloma humano (HPV) em citologia cervicovaginal. Jornal Brasileiro de Patologia, v.3 7, n. I, p. 57-61, 2001

17. PINTO, A. P.; CRUM, C. P. Natural history of cervical neoplasia: defining progression and its consequence. Clin Obstet Gynecol, v. 43, n. 2, p. 352-62, 2000

I8. PINTO, A. P.; TULIO, S.; CRUZ, O. R. HPV cofactors in cervical carcinogenesis. Rev Assoc Med Bras, v. 48, n. I, p. 73-8, 2002

19. PINTO, A. P. et al. Nonneoplastic findings in loop electrical excision procedure specimens from patients with persistent atypical squamous cells of uncertain significance in two consecutive pap smears. Diagn Cytopathol, v. 27, n. 2, p. 123-7, 2002

20. PINTO,A. P.et al. Limiting factors for cytopathological diagnosis of high-grade squamous intraepithelial lesions: a cytohistological correlation between findings in cervical smears and loop electrical excision procedure. Diagn Cytopathol, v. 26, n. I p. 15-8, 2002

21. PRASAD, C. J.; GENEST, D. R.; CRUM, CP. Nondiagnostic squamous atypia of the cervix (atypical squamous epithelium of undetermined significance):histologic and molecular correlates. Int J Gynecol Pathol, v. I3, n. 3, p. 220-7, 1994.

22. TRIVIIITSILP, P. et al. Papillary immature metaplasia (immature condyloma) of the cervix: a clinicopathologic analysis and comparison with papillary squamous carcinoma. Hum Pathol, v. 29, n. 6, p. 64 I-8, 1998

23.WARD, B. E. et al. Papillary immature metaplasia of the cervix: a distinct subset of exophytic cervical condyloma associated with HPV-6/II nucleic acids. Mod Pathol, v. 5, n. 4, p. 39I-5, 1992. 